\title{
Maternal and foetal outcome in term patients with previous one lower segment cesarean section
}

\author{
Meena Naresh Satia*, Kimaya A. Mali, Rakhi Sikarwar
}

Department of Obstetrics and Gynaecology, Seth Gordhandas Sunderdas Medical College and King Edward VII Memorial Hospital, Mumbai, Maharashtra, India

Received: 10 July 2016

Accepted: 05 August 2016

\section{*Correspondence:}

Dr. Meena Naresh Satia,

E-mail: meenasatia@kem.edu

Copyright: (c) the author(s), publisher and licensee Medip Academy. This is an open-access article distributed under the terms of the Creative Commons Attribution Non-Commercial License, which permits unrestricted non-commercial use, distribution, and reproduction in any medium, provided the original work is properly cited.

\begin{abstract}
Background: In modern day obstetric practice we encounter increasing number of patients with history of caesarean section because of rise in primary caesarean due to changing trends in their indications. There is increasing fear and anxiety by obstetricians for managing these cases from medico legal point of view. Present study was done to look at the feto-maternal outcome and for appropriate mode of delivery and overall to conduct the proper management of patients with previous one lower segment caesarean section so as to achieve the goal of healthy mother and baby at the end of pregnancy.

Methods: This is a Retrospective observational study carried out at G S Medical College and KEM Hospital, Parel Mumbai 12 Maharashtra India from January 2015 to December 2015. All patients enrolled in study were with H/O previous lower segment caesarean section. Classical CS, inverted $\mathrm{T}$ incision other medical complications were excluded. Patients were evaluated thoroughly by history and examination and mode of delivery was decided. Informed consent was taken of the patients who were fit for VBAC ie Vaginal Birth after caesarean section. Antenatal, intrapartum and post-partum records were evaluated. Women who were given trial of VBAC, progressed into labour spontaneously. Labour was constantly supervised by competent staff and meticulously monitored by CTG. Results: All the patients were counselled throughout their ANC period for VBAC Out of 7680 confinements 588 patients with previous one LSCS were encountered and among these patients 311 consented for vaginal birth and 277 underwent elective LSCS. From the 311 patients who consented for VBAC 165 delivered successfully 146 required Emergency LSCS. In VBAC group, 8 patients required foceps and in 2 patients required vaccum .There were 42 patients who underwent emergency LSCS for scar tenderness from which 10 patients had scar dehiscence and one patient had rupture uterus.

Conclusions: Successful vaginal delivery in patients with history of previous caesarean is associated with better outcomes than emergency caesarean section and hence proper counseling in ANC period and selection of patients for trial of VBAC is necessary, especially in underdeveloped nations where limited resources and facilities of fetomaternal monitoring are available.
\end{abstract}

Keywords: Previous caesarean delivery, Modern obstetric practice, VBAC

\section{INTRODUCTION}

Caesarean section is the most common surgery in obstetrics. Due to the rise in caesarean section rate in past few years, the number of patients with previous caesarean section has also increased. The CS epidemic is a reason for great concern in modern day practice since elective repeat caesarean section (ERCS) have remarkably increased. The secondary increase in repeat CS delivery has seen an increase in morbidity particularly increase in complications associated with abnormal placentation. There is no uniform policy regarding decision of mode of delivery in patients with previous caesarean section. In recent years, there has been increasing fear about the 
increase in morbidity associated with trial of labour after previous caesarean, particularly the complication of rupture uterus. ${ }^{1}$

Despite many studies being conducted regarding factors affecting the final result of VBAC like interval between previous caesarean and current pregnancy, indication of previous caesarean, H/O previous FTND following LSCS, postoperative surgical site infections etc. there are no standard guidelines for management of such patients whether to attempt VBAC or elective LSCS. Studies now prove that VBAC is a safer as compared to repeat elective caesarean section. ${ }^{2,3}$ Data regarding this issue are still inadequate in $3^{\text {rd }}$ world countries like India which prompted this study.

For fruitful outcome i.e. safe vaginal delivery after a previous caesarean section, it is mandatory that the obstetrician has adequate clinical judgement and skill to carefully select the patients, for VBAC because rupture of scar can be life-threatening. ${ }^{4}$ VBAC should be considered in cases of previous LSCS where the indication was a non- recurrent one. Incidence of repeat LSCS rate is increasing due to trend towards less or no trial of labour due to medico-legal anxiety.

The VBAC is also associated with complications like uterine rupture and maternal and perinatal morbidity and mortality hence the labour is to be monitored with utmost caution. The purpose of the study was to evaluate maternal and fetal outcomes in patients with history of previous one caesarean section presenting at term.

The dictum, "once caesarean section always caesarean section" no longer holds true. Once a caesarean always a hospital delivery is the dictum that means that every patient with a previous LSCS should have an institutional delivery. ${ }^{5}$ Various studies have suggested that in women with history of previous caesarean section for indication which is non-recurring, a trial of labour has less complications than elective repeat caesarean section.

The conservative approach trying to resist caesarean section arose from the concept of not compromising patient's obstetric career, because the dictum "twice a caesarean section always a caesarean section" holds true. ${ }^{4}$

There are multiple rewards of vaginal birth after caesarean section i.e. there is no abdominal surgery ,rapid convalescence, lower risk of SSI, less blood loss and therefore less need for blood transfusion. ${ }^{6}$ Also as far as the neonate is concerned there is less risk of RDS and iatrogenic prematurity. It also has psychosocial advantage i.e. most patients feel more positive emotionally about having a vaginal delivery versus a caesarean section.

The objective of this study was to study the maternal and fetal outcome in term patients with previous one lower segment caesarean section.

\section{METHODS}

The study was initiated after seeking approval from Institutional ethics committee. This is a hospital-based retrospective study which was conducted at a tertiary hospital from January 2015 to December 2015. We recruited all term cases of previous one LSCS who were registered in our ANC OPD as well as those patients who were referred to labour ward directly.

Following parameters were evaluated, route of delivery, Incidence of vaginal delivery following LSCS, incidence of scar dehiscence/scar rupture, maternal mortality and morbidity determined by anyone or more of the following: haemorrhage, blood transfusion requirement, viscus injury, wound infection, endometritis, hysterectomy and thromboembolism, perinatal outcome and NICU admissions

The case record forms of these previous LSCS patients were reviewed with respect to ANC profile and labour records. The Obstetric and fetal outcomes of the present pregnancy were studied and the results were noted and analyzed.

\section{Inclusion criteria}

All patients with history of previous one cesarean section at term were included in this study.

\section{Exclusion criteria}

History of uterine rupture, hysterotomy or previous uterine surgery like. Myomectomy, previous caesarean section scar other than lower segment transverse incision i.e. classical incision, $\mathrm{T}$ shaped incision or lower segment vertical incision. Any medical complications like Hypertension, diabetes mellitus, anaemia, heart disease, cardiac disease. And any fetal anomaly which could lead to mechanical difficulty at birth was also excluded.

\section{RESULTS}

Out of the total 6780 confinements over a period of one year from January 2015 to December 2015 we encountered 588 patients at term with the history of previous one LSCS as shown in Table 1.

Table 1: Incidence of previous LSCS patients.

\begin{tabular}{|lll|}
\hline $\begin{array}{l}\text { Total no. of } \\
\text { deliveries from } \\
\text { January 2015 to } \\
\text { December 2015 }\end{array}$ & $\begin{array}{l}\text { Total no. of case } \\
\text { with previous } \\
\text { caesarean section at } \\
\text { term }\end{array}$ & Incidence \\
\hline 6780 & 588 & $8.67 \%$ \\
\hline
\end{tabular}

The incidence of previous caesarean section cases is 8.67 $\%$. 
All the patients were counselled throughout their ANC period for VBAC. Out of total 588 patients 311 consented for vaginal birth and 277 underwent elective LSCS as shown in Figure 1.

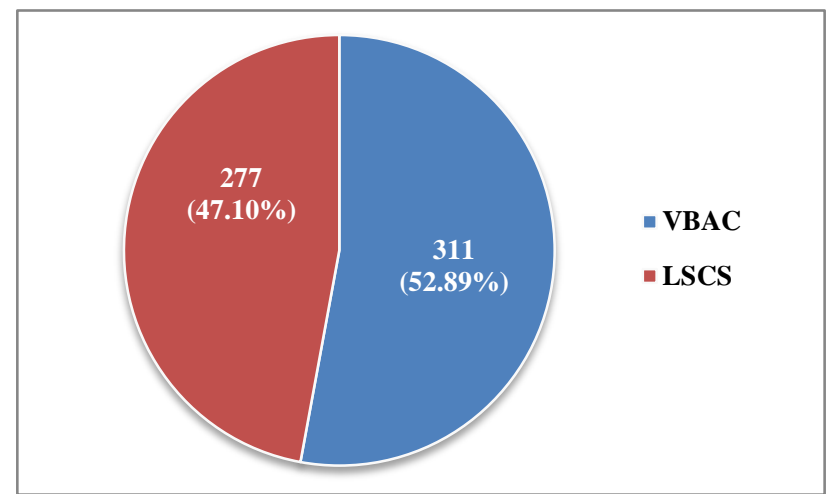

Figure 1: No. of patients consenting for VBAC.

Table 2: Outcome of the trial.

\begin{tabular}{|lcc|}
\hline $\begin{array}{l}\text { Outcome of trial } \\
\text { Total no of patients } \\
\text { who had a trial for }\end{array}$ & 311 & $52.8 \%$ \\
VBAC & 165 & $53 \%$ \\
\hline Sucessful VBAC & 146 & $46 \%$ \\
\hline Unsuccessful VBAC & 146 Percentage \\
\hline
\end{tabular}

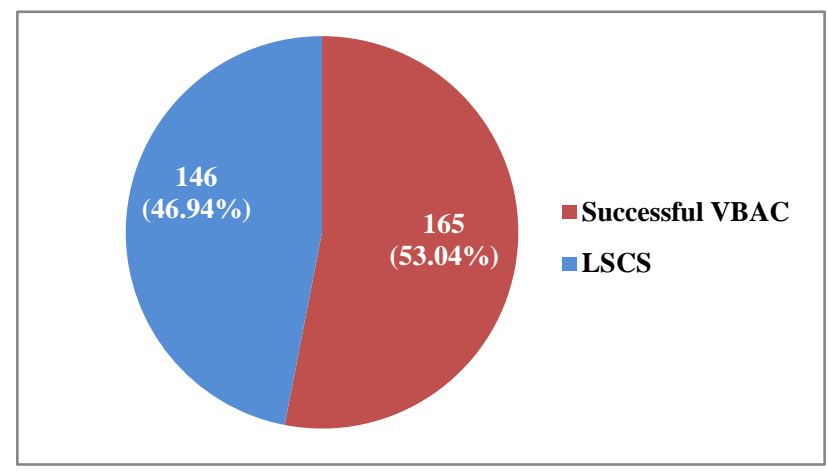

Figure 2: No. of successful VBAC.

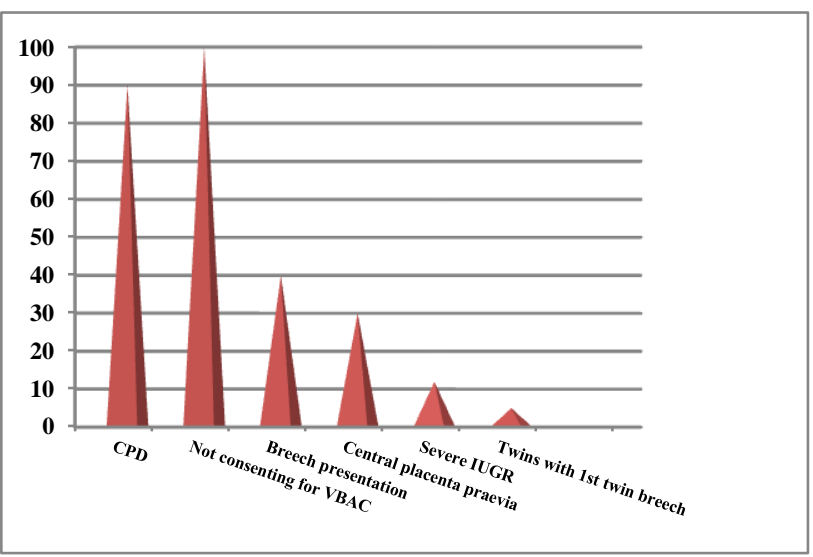

Out of 311 patients 146 patients had successful VBAC whereas 165 patients underwent emergency LSCS.

The indications of elective LSCS were CPD, placenta praevia, patients not willing for VBAC, IUGR and Breech presentations because in our setting trial of labour is usually not given to previous LSCS with breech presentation as shown in Figure 3.

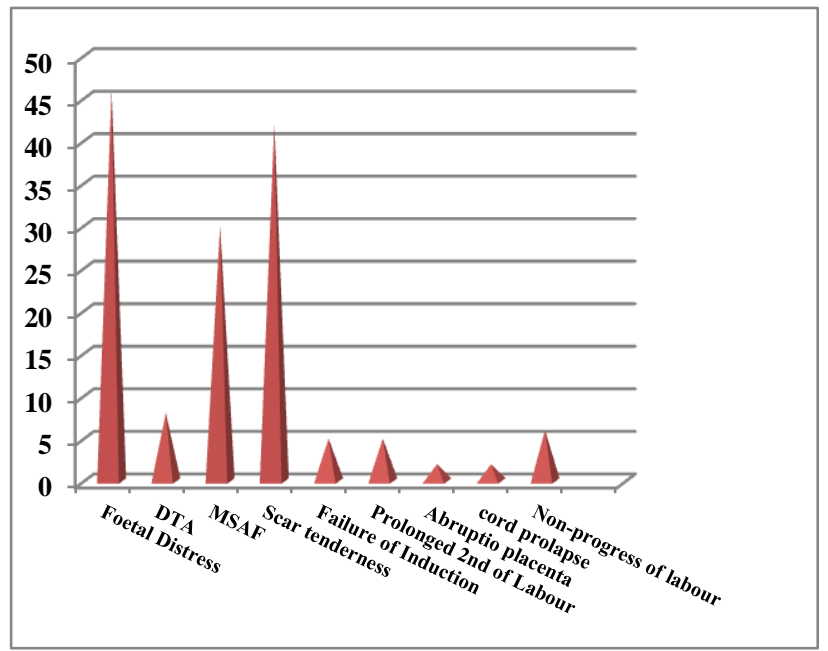

Figure 4: Indications of emergency LSCS.

Most common indication for emergency LSCS was fetal distress followed by scar tenderness and meconium stained amniotic fluid.

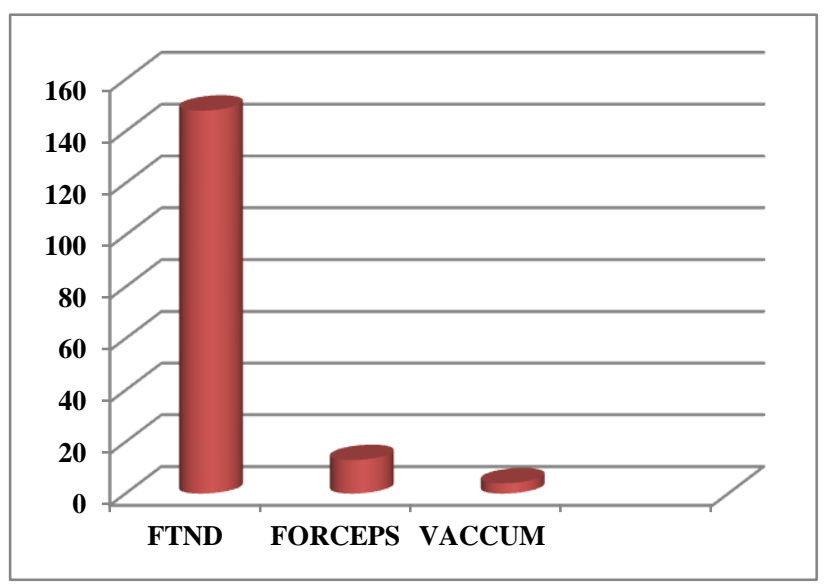

Figure 5: Mode of delivery among VBAC group.

There were 42 patients, who underwent emergency LSCS for scar tenderness from which 10 patients had scar dehiscence, giving percentage $3.1 \%$ as shown in Figure 6.

In the VBAC group, 10 patients required instrumental delivery, out of which 8 delivered by outlet forceps application and 2 required assistance by vacuum (Figure 5).

Figure 3: Indications of elective LSCS. 
Only 26 neonates out of 588 required NICU care.11 babies out of 26 required NICU stay following emergency LSCS of mothers who had consented for VBAC. 7 babies who delivered vaginally required NICU stay. 4 babies having low Apgar scores had fetal malformations further requiring NICU stay as shown in Figure 7.

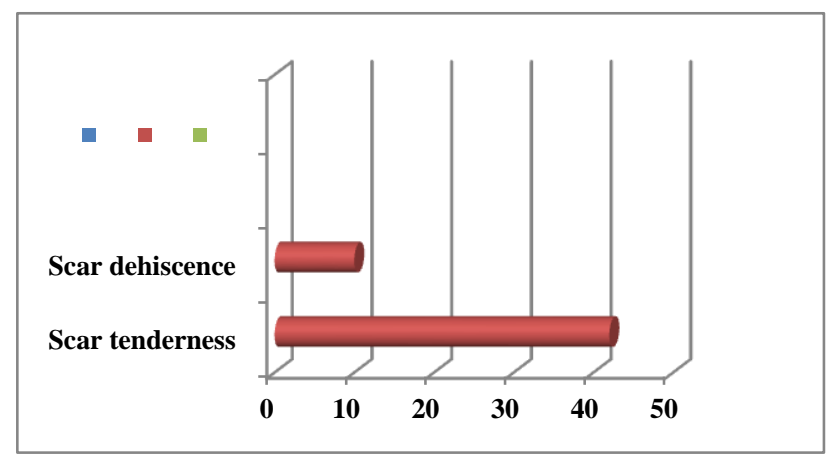

Figure 6: Emergency LSCS for scar tenderness.

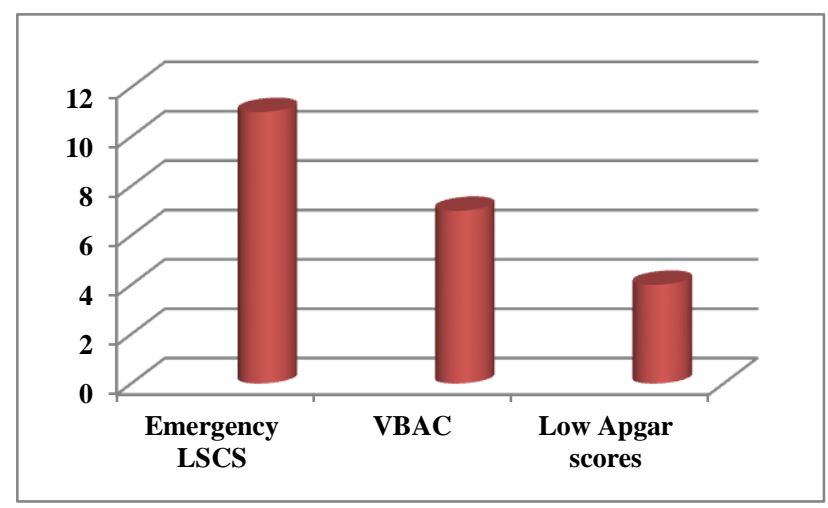

Figure 7: Neonatal outcome.

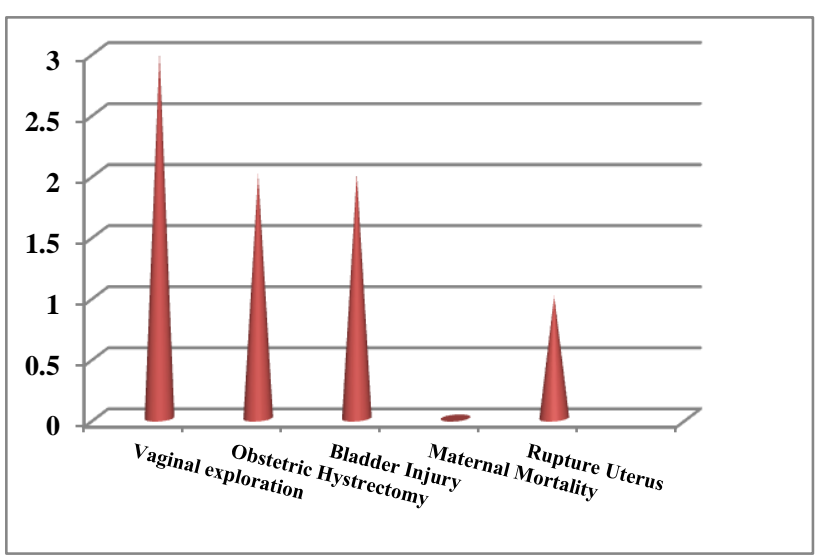

Figure 8: Maternal complications.

3 mothers underwent vaginal exploration following VBAC and 2 mothers had urinary bladder injury due to extensive adhesions between the lower uterine segment and the bladder and 1 patient required obstetric hysterectomy due to atonic variety of postpartum haemorrhage and 1 patient had adherent placenta requiring obstetric hysterectomy. One patient had uterine rupture which was repaired.

\section{DISCUSSION}

There is increasing concern by the obstetrician's world over for managing previous LSCS cases from medical and medico legal point of view. There is a widespread concern about the increasing proportion of births by caesarean section. ${ }^{7}$ Incidence of primary caesarean section rates is mounting rapidly and hence an increased proportion of the pregnant patients with $\mathrm{H} / \mathrm{O}$ of previous caesarean section are seen in day to day practice. Chances of success are high if there is history of prior vaginal delivery, spontaneous labour, ripe cervix and preterm delivery. Low chances of success are seen in short stature, obese patients, CPD and in patients with GDM. ${ }^{8}$ All Patients with a history of previous caesarean were counselled for VBAC. The percentage of women, who decline VBAC, is a determing factor of overall rates of caesarean birth. Data from recent studies suggest that VBAC may not be as safe as originally thought. ${ }^{9,10}$ But reports are conflicting and these factors along with medico legal concerns have led to a decline in clinician's attitude for offering VBAC and also women not accepting trial for VBAC in various parts of the world. ${ }^{11,12}$ The present study evaluated the outcome and trends in patients with a history of prior LSCS who delivered in KEM Hospital from January 2015 to December 2015. Out of 7680 patients who delivered in our hospital during the study period, 588 term patients had a history of one previous LSCS, accounting for $8.6 \%$ of the total number of patients. This incidence is comparable to the recent study by Landon et al who reported $12.16 \% .^{9}$

Out of the 588 patients in our study, $52.8 \%$ gave consent for a trial for VBAC as against $39.90 \%$ of the patients in the study by Landon et al and $64 \%$ by Gonen and Colleagues as shown in Table 3.,13

Table 3: Comparative study of participants consented for trial of VBAC.

\begin{tabular}{|ll|}
\hline Landon et al & $39.9 \%$ \\
\hline Gonen and colleague & $64 \%$ \\
\hline Present study & $52.8 \%$ \\
\hline
\end{tabular}

As reported in various studies the overall rate of vaginal delivery following previous caesarean delivery varies from $28 \%$ to $51 \%$. Gonen and colleagues from Nigeria reported $51.22 \%$ of patients delivering vaginally. Chattopadhyay and colleagues reported an incidence of $40 \%$ and Landon et al reported an incidence of $28.57 \%$. $^{14}$ Our study is comparable to this, with $53 \%$ of the patients delivering vaginally and $46 \%$ of our patients culminated in emergency LSCS as shown in Table 4. 
Table 4: Comparative studies of Successful VBAC.

\begin{tabular}{|lllll|}
\hline Landon et al & Gonen and colleagues & Chattopadhyay and colleagues & Anagha et al ${ }^{14}$ & Bangal et al \\
\hline $28.57 \%$ & $51.22 \%$ & $40 \%$ & $46.7 \%$ & $85 \%$ \\
\hline
\end{tabular}

Table 5: Comparative study of ERCS for unwillingness for VBAC.

\begin{tabular}{|ll|}
\hline Gonen and colleagues & $37.90 \%$ \\
\hline Present study & $36.1 \%$ \\
\hline
\end{tabular}

The most common indication for an Elective CS in the present study was the unwillingness of the patient for a VBAC in spite of being eligible for a trial for VBAC. 100 patients out of 277 elective sections i.e. $36.1 \%$ of the total number of patients who opted for elective LSCS were not willing for VBAC despite being eligible for trial of VBAC. As shown in Table 5 this is relatively similar to the study by Gonen and colleagues, where $37.90 \%$ of the patients had an ERCS as these patients did not consent for VBAC. ${ }^{13}$

Scar dehiscence, defined as a disruption of the uterine muscle with serosa intact was seen in 10 patients out of 311 patients who consented for VBAC giving an incidence of $3.1 \%$ in the present study. As shown in Table 6 This is comparable to the incidence quoted by Bangal et al, which was $2 \%$. In the present study, maternal morbidity was noted in 14 patients who had a repeat CS and in only 3 patients who had a trial for VBAC requiring vaginal exploration. Maternal complications in cases of elective CS in one patient were due to atonic PPH and another patient had adherent placenta that required obstetric hysterectomy and blood transfusion. There was one case of uterine rupture in the present study. The risk of $0.5 \%$ of uterine rupture should be discussed with the woman, which can be life threatening for both the mother and the baby. Intraabdominal findings of adhesions and advancement of the bladder on the lower segment which presented difficulties in separating the bladder and accidental bladder injury was seen in 2 patients. It has generally been accepted that vaginal delivery has less number of complications as far as maternal outcome is concerned than repeat CS. Our results are relatively similar to an earlier meta-analysis comparing ERCS versus trial for VBAC. ${ }^{16}$ In the present study, there was no maternal mortality noted. There is ample evidence in literature which suggests that ERCS does not decrease fetal or maternal mortality but instead further increases costs borne out of increased hospital stay and maternal morbidity. ${ }^{17}$

Table 6: Comparative statistics of maternal morbidity following VBAC.

\begin{tabular}{|lllllll|l|}
\hline & $\begin{array}{l}\text { Gonen and } \\
\text { colleagues }\end{array}$ & $\begin{array}{l}\text { RCOG green } \\
\text { top guidelines }\end{array}$ & $\begin{array}{l}\text { Lydon - } \\
\text { Rochelle et a }{ }^{18}\end{array}$ & $\begin{array}{l}\text { Zelop } \\
\text { et al }\end{array}$ & $\begin{array}{l}\text { Bangal } \\
\text { et al }\end{array}$ & $\begin{array}{l}\text { Anagha } \\
\text { et al }\end{array}$ & $\begin{array}{l}\text { Present } \\
\text { study }\end{array}$ \\
\hline $\begin{array}{l}\text { Failure of } \\
\text { VBAC }\end{array}$ & $36.1 \%$ & $53.3 \%$ & & & $15 \%$ & $53.3 \%$ & $46 \%$ \\
\hline Scar dehiscence & 2.75 & & & & $2 \%$ & $2.75 \%$ & $3.1 \%$ \\
\hline $\begin{array}{l}\text { Risk of rupture } \\
\text { uterus }\end{array}$ & 0 & $0.5 \%$ & $0.52 \%$ & $0.72 \%$ & & $0 \%$ & $0.3 \%$ \\
\hline
\end{tabular}

Current recommendations of the RCOG and ACOG include offering the option of a planned VBAC to women with a prior history of one uncomplicated LSCS in an otherwise normal pregnancy at term without any contraindication to vaginal birth. ${ }^{20}$ Proper antenatal counseling regarding the benefits and risks associated with a planned VBAC should be emphasized. A final decision for mode of birth must be agreed upon before the expected date of delivery. In the absence of large scale RCTs comparing trial for VBAC and ERCS, there is a large scope for future research in 'birth after previous caesarean birth' and priorities have to be identified in this respect. A simple and pragmatic method or scoring system for quantifying the risk of emergency caesarean delivery and its complications in patients who are willing for VBAC is required. This will help identify women at high risk for an unsuccessful VBAC and would thus help decision making considerably.

\section{CONCLUSION}

With the advent of newer technologies for monitoring during labor, patients should be counselled for VBAC right from ANC period. Because rupture of scar can be life threatening to the mother and the child. Therefore for successful vaginal delivery after a prior caesarean section, the obstetrician needs to have skill and experience to select the patients carefully for trial of vaginal birth. VBAC should be considered in cases of previous one caesarean section done for indications that 
are non-recurrent and it should always be attempted in institutions well equipped to respond to emergencies, with an OT facility and adequate trained personnel to provide emergency care. There is lesser hospital stay and early recovery in VBAC than ERCS. Hence it would be safe to conclude that a trial for VBAC after a prior LSCS constitutes a safe form of obstetrical management.

Funding: No funding sources

Conflict of interest: None declared

Ethical approval: The study was approved by the Institutional Ethics Committee

\section{REFERENCES}

1. Jones RO, Nagashima AW, Hartnett-Goodman MM, Goodlin RC. Rupture of low transverse cesarean scars during trial of labor. Obstet Gynecol. 1991;77:815-7.

2. Cahill AG, Stamilio DM, Odibo AO, Peipert JF, Ratcliffe SJ, Stevens EJ, et al. Is vaginal birth after cesarean (VBAC) or elective repeat cesarean safer in women with a prior vaginal delivery? Am J Obstet Gynecol. 2006;195:1143-7.

3. Durnwald CP, Rouse DJ, Leveno KJ. The maternalfetal medicine units cesarean registry: safety and efficacy of a trial of labor in preterm pregnancy after a prior cesarean delivery. Am J Obstet Gynecol. 2006;195:1119-26.

4. Vhawal V, Nayani Z, Kshirsagar NS, Laddad MM, Nagar S. Trial of vaginal delivery after one caeserean section. Journal of Evolution of Medical and Dental Sciences. 2014;3(62):13708-15.

5. Bangal VB, Giri PA, Shinde KK, Gavhane SP. Vaginal birth after cesarean section. N Am J Med Sci. 2013;5(2):140-4.

6. Jani RS, Munshi DS. Management of pregnancy with previous lower segment caesarean section in modern obstetric: NHL Journal of Medical Sciences. 2013;2(2):59-63.

7. Parliamentary office of science and technology. Caesarean sections. Postnote. 2002;184:1-4.

8. RCOG green top guideline No. 45. Birth after previous caesarean birth, 2007. Available at https://www.rcog.org.uk/globalassets/documents/gui delines/gtg4511022011.pdf.

9. Landon MB, Hauth JC, Leveno KJ, Spong CY, Leindecker S, Varner MW, et al. Maternal and
Perinatal outcomes associated with a trial of labour after prior caesarean delivery. $\mathrm{N}$ Engl $\mathrm{J}$ Med. 2004;351:2581-9.

10. Smith GC, Pell JP, Cameron AD, Dobbie R. Risk of perinatal death associated with labor after previous caesarean delivery in uncomplicated term pregnancies. JAMA. 2002;287:2684-90.

11. Menacker F, Curtin SC. Trends in caesarean birth and vaginal birth after previous caesarean. 1991-99. Natl Vital Stat Rep. 2001;49:1-16.

12. Yeh J, Wactawski-Wende J, Shelton JA. Reschke J. Temporal trends in the rates of trial of labor in low risk pregnancies and their impact on the rates and success of vaginal birth after caesarean delivery. Am J Obstet Gynecol. 2006;194:144.

13. Gonen R, Nisenblat V, Barak S, Tamir A, Ohel G. Results of a well-defined protocol for a trial of labour after prior caesarean section. Obstet Gynecol. 2006;107:240-5.

14. Chattopadhyay K, Sengupta B, Edress Y, Lambourne A. Vaginal birth after caesarean section: management debate. Am J Obstet Gynaecol. 1988;26:189.

15. Jinturkar AA, Dongaonkar D. Study of obstetric and fetal outcome of post caesarean section pregnancy international. Journal of Recent Trends in Science and Technology. 2014;10(3):530-7.

16. Petrie R, Richart R, Strassar J, Cohen W. Is caesarean section cost effective? Contempt Obstet Gynaecol. 1982;19:161.

17. Shy L, Logerfo J, Karp L. Evaluation of elective repeat caesarean section as a standard of care. Am J Obstet Gynecol. 1981;139:123.

18. Lydon-Rochelle M, Holt VL, Easterling TR, Martin DP. Risk of uterine rupture during labor among women with a prior cesarean delivery. N Engl J Med. 2001;345(1):3-8.

19. Zelop CM, Shipp TD, Repke JT, Cohen A, Caughey $\mathrm{AB}$, Lieberman E. Uterine rupture during induced or augmented labor in gravid women with one prior cesarean delivery. Am J Obstet Gynecol. 1999;181(4):882-6.

20. Vaginal birth after previous caesarean delivery. American College of Obsetricians and Gynecologists Committee on Obstetric Practice Bulletins. ACOG Practice Bulletin No. 54: Obstet Gynecol. 2004;104:203-12.

Cite this article as: Satia MN, Mali KA, Sikarwar R. Maternal and foetal outcome in term patients with previous one lower segment caesarean section. Int J Reprod Contracept Obstet Gynecol 2016;5:3075-80. 